\title{
Reversible Control of Crystalline Rotors by Squeezing Their Hydrogen Bond Cloud Across a Halogen Bond-Mediated Phase Transition
}

Cyprien Lemouchi, ${ }^{\dagger, \bigcirc}$ Hiroshi M. Yamamoto, ${ }^{\ddagger}, \bullet$ Reizo Kato, ${ }^{\ddagger}$ Sergey Simonov, ${ }^{\S}$ Leokadiya Zorina, ${ }^{\S}$ Antonio Rodríguez-Fortea, " Enric Canadell, ${ }^{\#}$ Pawel Wzietek, ${ }^{\perp}$ Konstantinos Iliopoulos, ${ }^{\dagger}$ Denis Gindre, ${ }^{\dagger}$ Michael Chrysos, ${ }^{\dagger}$ and Patrick Batail ${ }^{*}, \dagger$

${ }^{\dagger}$ Laboratoire MOLTECH-Anjou, Université d’Angers, CNRS UMR 6200, 2 Boulevard Lavoisier, 49045 Angers, France
${ }^{\ddagger}$ RIKEN, 2-1 Hirosawa, Wako-shi, Saitama 351-0198, Japan
${ }^{\S}$ Institute of Solid State Physics, Russian Academy of Sciences, 142432 Chernogolovka MD, Russia
${ }^{\|}$Departament de Química Física i Inorgànica, Universitat Rovira i Virgili, Marcel-lí Domingo s/n, 43007 Tarragona, Spain
${ }^{\#}$ Institut de Ciència de Materials de Barcelona (ICMAB-CSIC), Campus de la UAB, 08193, Bellaterra, Spain
${ }^{\perp}$ Laboratoire de Physique des Solides, Université de Paris-Sud, CNRS UMR 6502, Bâtiment 510, 91405 Orsay, France

Supporting Information

ABSTRACT: We report on a crystalline rotor that undergoes a reversible phase transition at $145 \mathrm{~K}$. Variable-temperature X-ray and ${ }^{1} \mathrm{H}$ spin-lattice relaxation experiments, and calculations of rotational barriers, provide a description (i) of the way in which the rotators' dynamics changes back and forth at the onset of the phase transition and (ii) of the mechanism responsible for the abrupt switching of the crystalline rotors from a very low-energy 4-fold degenerate equilibrium state, in which the rotation is ultrafast $(9.6 \mathrm{GHz}$ at $145 \mathrm{~K})$, to a single higher-energy state associated with a slower motion $(2.3 \mathrm{GHz}$ at $145 \mathrm{~K})$. Our results provide evidence that the reversible change observed in the rotational barriers at the transition is due to a cooperative modulation of the $\mathrm{C}-\mathrm{H}_{\text {rotator }} \cdots \mathrm{I}_{\text {stator }}$ hydrogen bond cloud across a $\mathrm{C}-\mathrm{I}_{\text {stator }} \cdots \mathrm{I}_{\text {stator }}-\mathrm{C}$ halogen bond-mediated
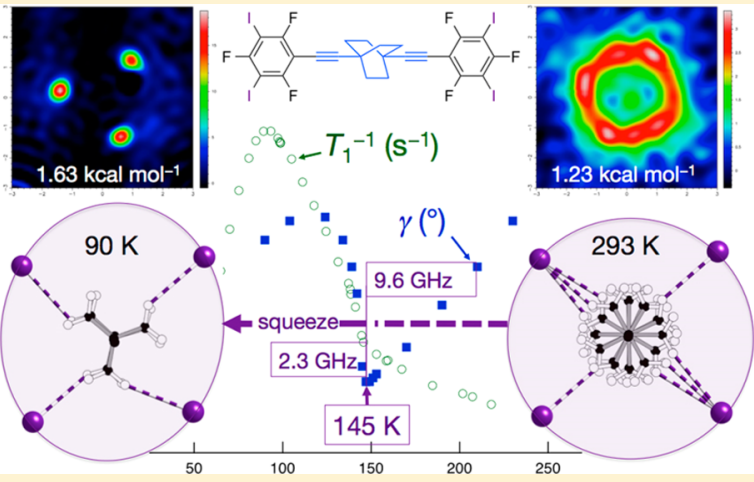
phase transition. In addition, we report evidence for second-harmonic generation from this material, thereby confirming with a second example the benefit of using polarized light to probe the torsional degree of freedom of chiral helix blades, as well as symmetry and dimensionality of large collections of chiral rotors in the solid state.

\section{INTRODUCTION}

The control of dynamic molecular systems at the nanoscale level is a highly timely and essential issue for the development of complex functional molecular constructs, ${ }^{1}$ among which artificial crystalline rotors ${ }^{2-9}$ and switches. ${ }^{5 b, 7-11}$ Here, we report on crystalline arrays of the molecular rotor ${ }^{12} 2$ (Scheme 1) whose dynamics responds to variations of the rotators ${ }^{, 12}$ environment across a phase transition. Materials design that includes deliberate use of halogen- and hydrogen-bonding interactions, as well as variable-temperature X-ray and ${ }^{1} \mathrm{H}$ spinlattice relaxation experiments $\left(T_{1}\right)$, and calculations of rotational barriers, provide an in-depth understanding of the switching mechanism of the rotational barriers and of the frequency of associated rotational motion. In this article, we delve into these issues, describing how at the onset of a phase transition $(145 \mathrm{~K})$ the solid becomes active and highly responsive, and how cooperative modulation of the $\mathrm{C}-$ $\mathrm{H}_{\text {rotator }} \cdots \mathrm{I}_{\text {stator }}$ cloud defining the rotator's environment acts to modify the rotator's dynamics. Further to the report of an abrupt, reversible change of $T_{1}^{-1}$ (and its interpretation) in a crystalline rotor, our results are seen as of fundamental relevance to the design of nanomachines. ${ }^{1}$

By targeting 2 we decided to follow up on our recent work on the BIBCO system ${ }^{3}$ anticipating self-assembly by halogen bonding ${ }^{13-17}$ (Scheme 1) with the additional benefit of delivering, besides $p$-BIB ${ }^{14 a, 15}$ and others ${ }^{15}$ shown in Scheme 2 , a novel rigid organic strut yet with a rotating 1,4-bis(ethynyl) bicyclo[2.2.2] octane (BCO) core to serve as a neutral, functional spacer in the design of halogen-bonded metallic conductors and superconductors. ${ }^{14-16}$ It is interesting to note that, in addition to offering opportunities for designing hybrids of molecular conductors and molecular rotors, ${ }^{4}$ molecular units with a BCO core are expected to have an enhanced solubility compared to rigid struts ${ }^{15}$ with static phenyl cores (Scheme 2).

Received: February 28, 2014

Revised: April 26, 2014

Published: May 9, 2014 
Scheme 1

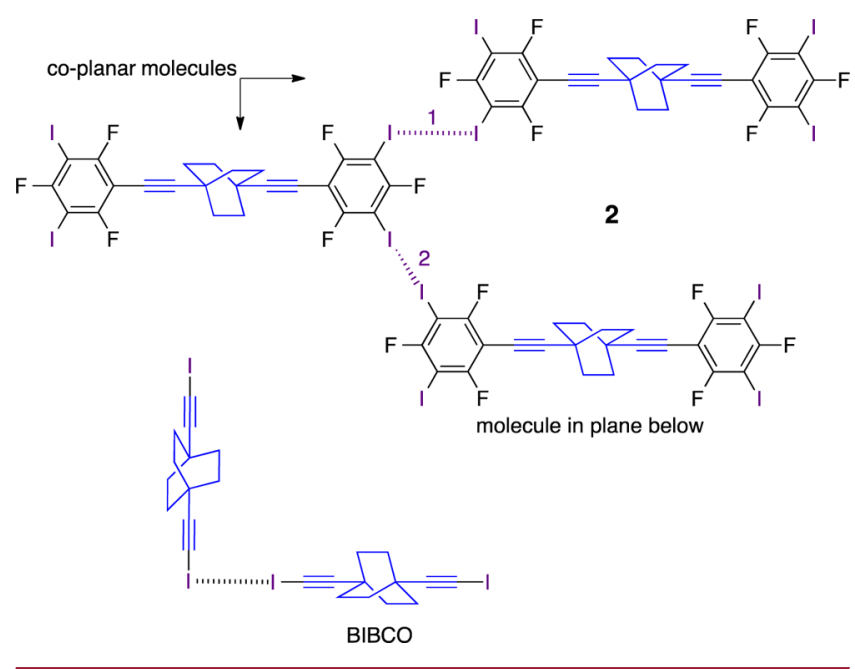

Scheme 2

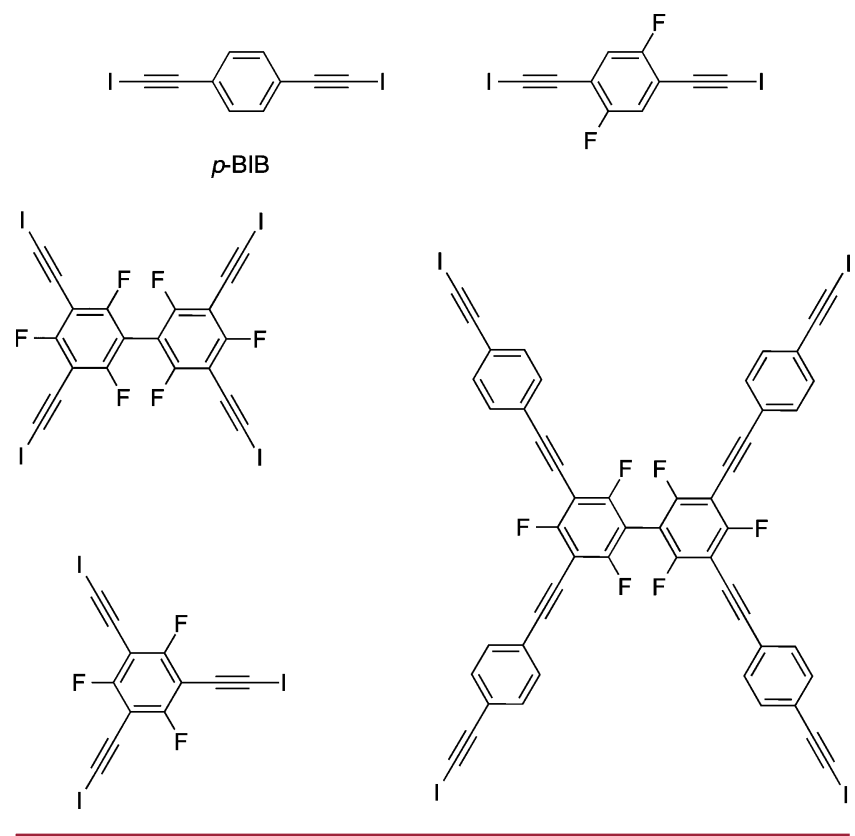

RESULTS AND DISCUSSION

Synthesis of Compound 2. The two-step synthesis involves two Sonogashira couplings by reacting 1,3,5-trifluoro2,4,6-triiodobenzene on 1,4-bis(ethynyl) bicyclo[2.2.2] octane (Scheme 3). Note that all three iodine atoms on the phenyl core have identical reactivity; that is, there is no selectivity in Sonogashira-coupling reactions bond to yield a complex mixture of monomers and polymers. In this respect, it is likely that the desirable $C_{2}$-symmetry bisubstituted molecules 2 can be obtained (yet in minute amounts) as indeed observed by mass spectroscopy.

Note that, in this context, the extensive use of recycling size exclusion chromatography (SEC) in THF turned out to be quite efficient in performing the purification of the complex highly diluted triethylamine reaction mixture. Thus, $\mathbf{1}$, the monosubstituted majority product of a single Sonogashira coupling, was characterized by mass spectroscopy. Note that this first step also yielded some small amounts of both 2 and 3 . Therefore, the majority product $\mathbf{1}$ was again engaged in a subsequent Sonogashira coupling to afford $\mathbf{2}$ after SEC purification, in $44 \%$ yield. Plate-like colorless single crystals of good quality were obtained by slow evaporation of a THF solution.

A Stator-Stator Halogen-Bonded System. There is one-half equivalent molecule in the asymmetric unit of the room temperature structure (Table S1, Supporting Information). As shown in Figure 1, rigid rods 2 self-assemble by a C$\mathrm{I} \cdots \mathrm{I}-\mathrm{C}$ bond (bond 1 in Scheme 1) in a two-dimensional array. An additional halogen bond (bond 2 in Scheme 1 and Figure 1b) connects the layers together in the interlayer transverse direction. Note that the molecular rods are all aligned in the crystal. Therefore, the system may be described as a onedimensional crystalline array of stator-stator halogen bonded rotors with a single common director for the rotators' axles.

Rotator Distributed over Four Equilibrium Positions at 293 K. Remarkably, the bicyclo[2.2.2] octane rotator is distributed over four equilibrium positions on its single crystallographic site (Figures 1a,b and 2) in the $293 \mathrm{~K}$ structure. This is a striking, unprecedented feature since such rotors in $\mathrm{BIBCO},{ }^{3}$ 1,4-bis(carboxyethynyl)bicyclo[2.2.2] octane $(\mathrm{BABCO}){ }^{4}\left[n \mathrm{Bu}_{4} \mathrm{~N}^{+}\right]_{2}[\mathrm{BABCO}]\left[\mathrm{BABCO}^{-}\right]_{2},{ }^{4}$ (EDT-TTF$\left.\mathrm{CONH}_{2}\right)_{2}^{+}\left[\mathrm{BABCO}^{-}\right],{ }^{4}$ and the dirotor, bis((4-(4-pyridyl)ethynyl)bicyclo [2.2.2] oct-1-yl)buta-1,3-diyne ${ }^{5}$ (Table 1) have been shown to be distributed over one or two equilibrium positions. The occurrence of four equilibrium positions is seen as an early indication that, at this temperature, the rotators rub rather mildly onto their environment in the crystal and lead one to expect a rather low rotational barrier at room temperature (typically $1 \mathrm{kcal} \mathrm{mol}^{-1}$ or less) that is in the lower limit of those recorded to date. ${ }^{2 a}$

Change in Halogen Bonding and Rotators' Equilibrium Position below Phase Transition at $145 \mathrm{~K}$. The temperature dependence of the unit cell parameters reveals the onset of a phase transition at ca. $145 \mathrm{~K}$ (Figure 3 and Figure S1) followed by a gradual change of the unit cell parameters over $20 \mathrm{~K}$. A full structure determination, carried out in the low-temperature phase at $90 \mathrm{~K}$, concludes that a reversible triclinic-to-triclinic phase transition along with a doubling of the unit cell has occurred.

There are two major structural features that change at the transition (Figures 1c and 4). In the first one, the single inplane C-I...I-C halogen bond (bond 1 in Scheme 1) at 3.991 $\AA$ in the room-temperature structure (Figure $1 \mathrm{~b}$ ) is transformed into two different bonds: a longer one ( $4.188 \AA$, purple in-plane dashed line at $c / 2$ in Figure 1c) and a shorter one (3.796 $\AA$, white and red cylinders at $c=0$ and $c=1$ in Figure 1c) (Table S2, Supporting Information). Note in Figure 4 how the tightening in bond length and the increasing by $20^{\circ}$ of the $\angle \mathrm{C}-\mathrm{I} \cdots \mathrm{I}$ angle of the halogen bond in the $a b$ planes are associated with a significant change in the relative orientation of the molecular rods. Therefore, on account of the lattice reconstruction by this salient modification of the halogen-bond manifold, any rotator is sandwiched in between two different planes in the low-temperature phase instead of two identical planes at room temperature. The second structural feature has to do with the rotator itself within the full independent molecule in the doubled asymmetric unit: a single equilibrium position was identified at $90 \mathrm{~K}$ in Figures $1 \mathrm{c}, 2$, and $6 \mathrm{~b}$. We then conducted ${ }^{1} \mathrm{H}$ spin-lattice relaxation experiments to probe and characterize this change in the system's dynamics observed by X-ray at the structural transition.

Reversible Change in ${ }^{1} \mathrm{H}$ Spin-Lattice Relaxation at $140 \mathrm{~K}$. Variable-temperature $(35-300 \mathrm{~K})$ proton spin-lattice 
Scheme 3
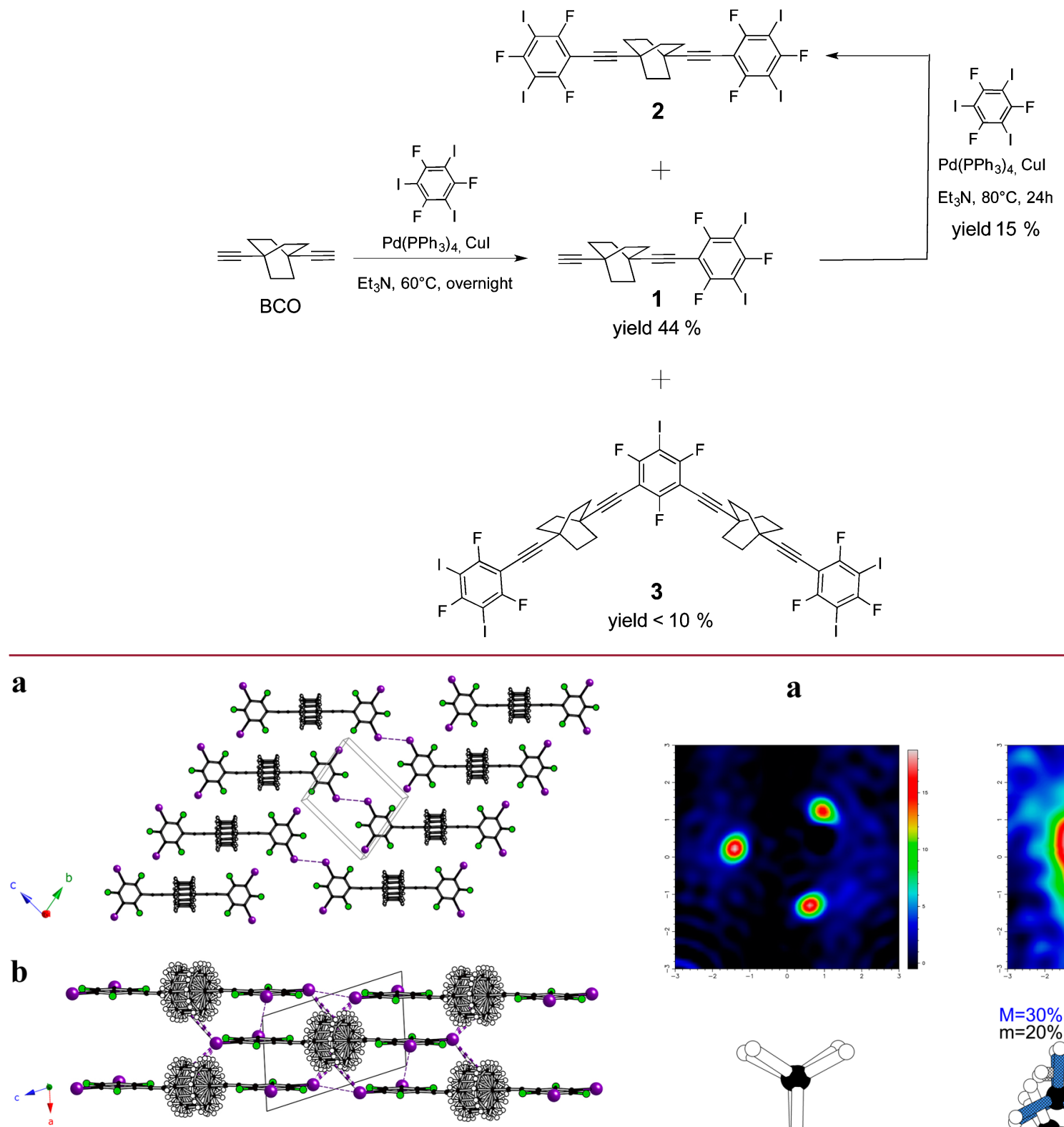

c

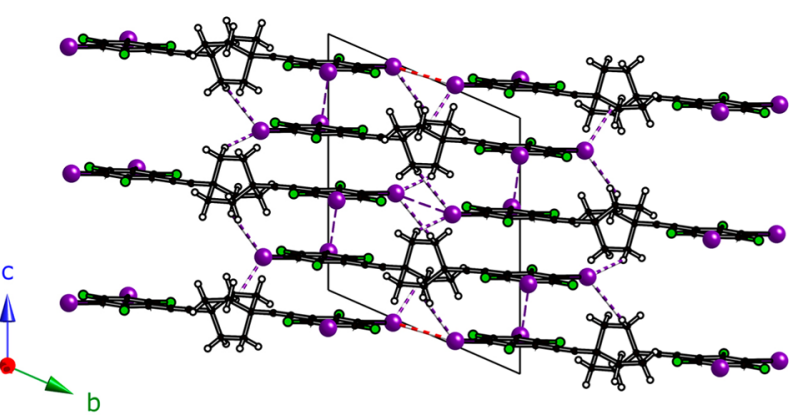

Figure 1. (a) A single halogen-bonded (dashed line) layer of 2 at 293 K; (b) interlayer interaction at $293 \mathrm{~K}$ (halogen bonds: dashed lines; hydrogen bonds: white and purple two-band cylinders); (c) doubled cell $\left(b_{90 \mathrm{~K}}=(a-c)_{293 \mathrm{~K}}\right)$ and interlayer interactions at $90 \mathrm{~K}$ (halogen bonds: dashed lines and white and red two-band cylinders; hydrogen bonds: white and purple two-band cylinders).

relaxation experiments, ${ }^{1} \mathrm{H} T_{1}{ }^{-1}$, ${ }^{2-5}$ carried out at a ${ }^{1} \mathrm{H}$ Larmor frequency of $55 \mathrm{MHz}$ on a static single crystal reveal a

a
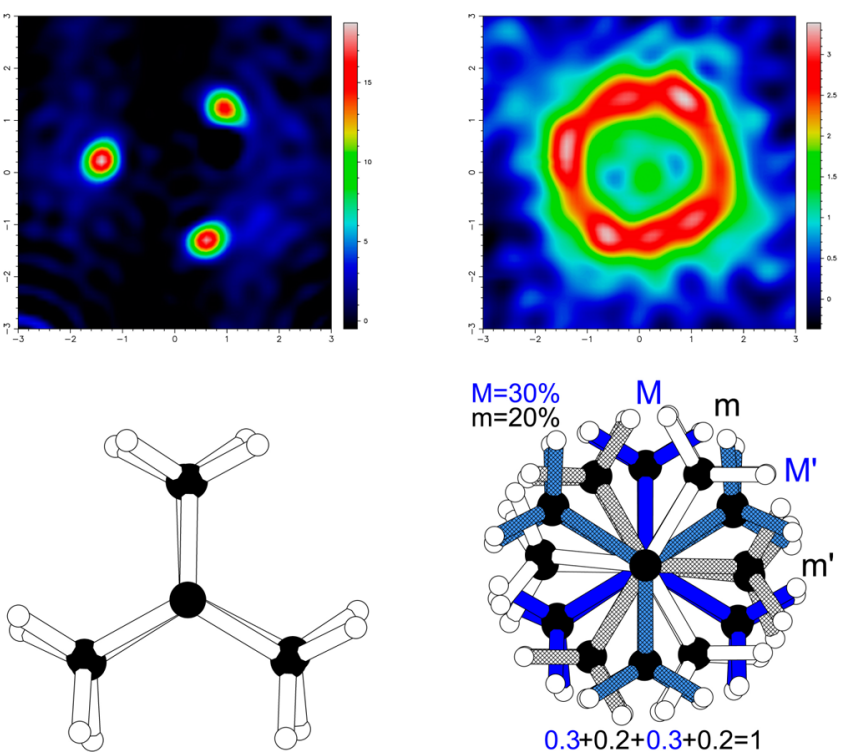

Figure 2. Experimental electron density patterns and refined rotator's positions for 2: (a) one equilibrium position at $90 \mathrm{~K}$; (b) four equilibrium positions at $293 \mathrm{~K}$. Note that the occupancies for the four equilibrium positions ( $\mathrm{M}$ for majority; $\mathrm{m}$ for minority) at $293 \mathrm{~K}$ are slightly unbalanced.

reversible discontinuity at the temperature of the structural transition (Figure 5; onset: $145 \mathrm{~K}$; midpoint defined by red line: $140(1) \mathrm{K})$. While the occurrence of two relaxation processes has either typically been associated with rotors on two different crystallographic sites in $\mathrm{BIBCO}^{3}$ and $\left[n \mathrm{Bu}_{4} \mathrm{~N}^{+}\right]_{2^{-}}$ $[\mathrm{BABCO}]\left[\mathrm{BABCO}^{-}\right]_{2}$, or to a correlated disrotatory motion in pairs of rotors in the tetrayne system bis((4-(4-pyridyl)ethynyl)bicyclo[2.2.2] oct-1-yl)buta-1,3-diyne (Table 1), ${ }^{5}$ the present unprecedented discontinuity in the $T_{1}^{-1}$ data led us to 
Table 1. Arrhenius Parameters Derived from Fits at Two Fields of the $T_{1}{ }^{-1}$ Data to the Kubo-Tomita Equation, $\tau_{\mathrm{c}}=\tau_{0} \exp \left(E_{\mathrm{a}} /\right.$ $k T$ ) for Functional 1,4-Bis(ethynyl)bicyclo[2.2.2] octane Crystalline Rotors

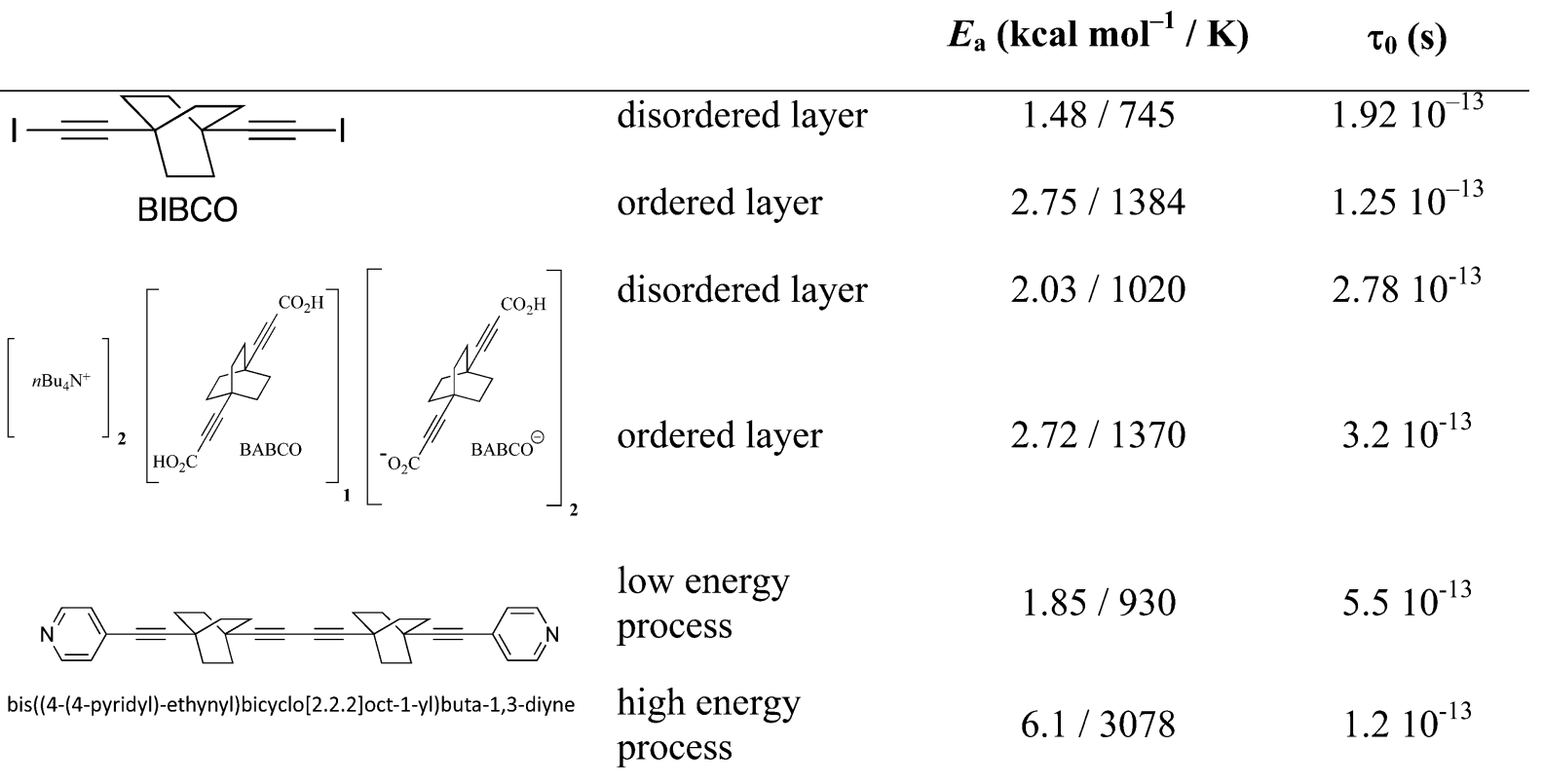

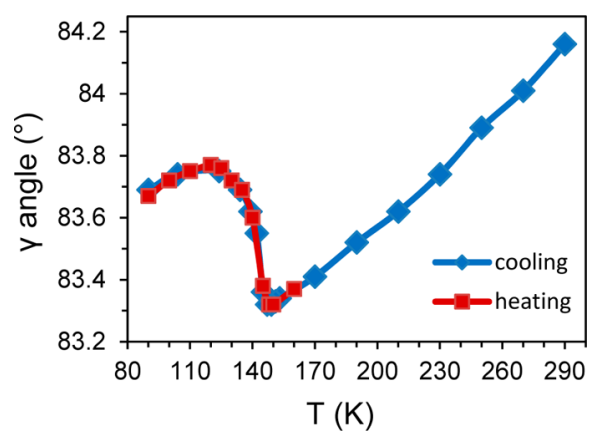

Figure 3. Temperature dependence of the triclinic unit cell angle $\gamma$ $\left(\gamma_{293 \mathrm{~K}}=180^{\circ}-\beta_{90 \mathrm{~K}}\right)$ of 2 .

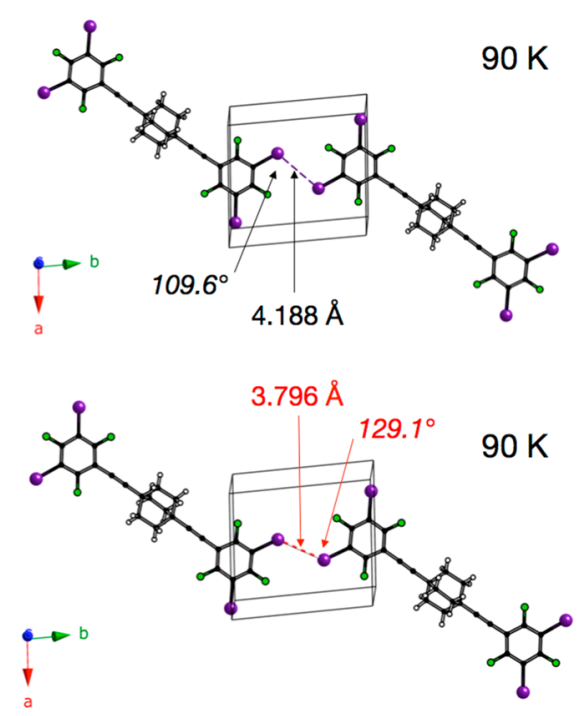

Figure 4. Geometry of the two in-plane C-I $\cdots \mathrm{I}-\mathrm{C}$ bonds in the $90 \mathrm{~K}$ structure of 2 .

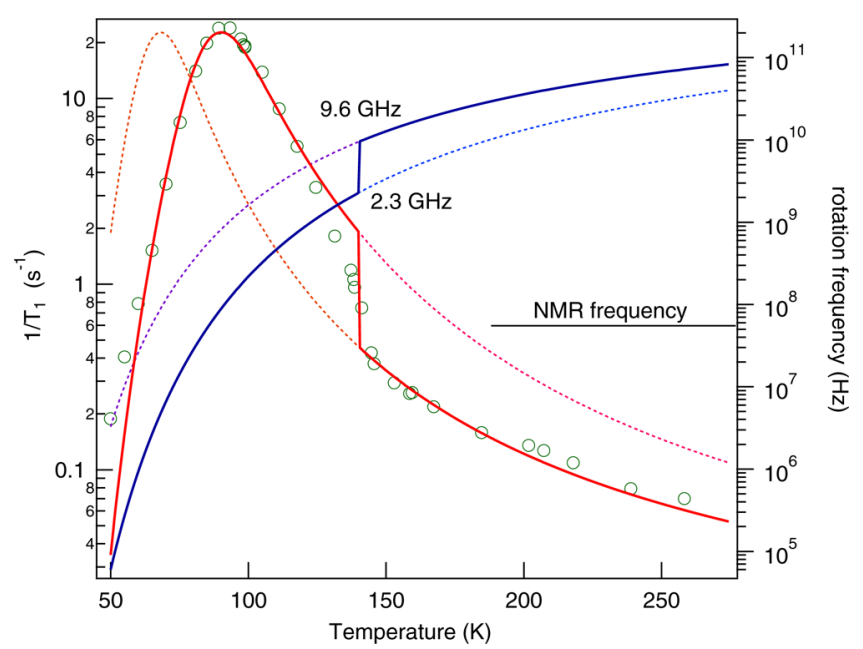

Figure 5. Variable temperature ${ }^{1} \mathrm{H}$ spin-lattice relaxation time $T_{1}{ }^{-1}$ at $55 \mathrm{MHz}$ for 2 . The dotted red lines represent the fit of the data to the Kubo-Tomita formula, $\tau_{\mathrm{c}}=\tau_{0} \exp \left(E_{\mathrm{a}} / k T\right)$, above and below the transition, yielding $E_{\mathrm{a}}=620 \mathrm{~K}\left(1.23 \mathrm{kcal} \mathrm{mol}^{-1}\right)$ and $E_{\mathrm{a}}=820 \mathrm{~K}(1.63$ $\left.\mathrm{kcal} \mathrm{mol}^{-1}\right)$, respectively. The solid red line emphasizes the discontinuity at the transition. The solid blue line represents the rotational frequency above and below the phase transition calculated with the Kubo-Tomita formula using the former activation energies. The rotational frequency decreases with decreasing temperature and abruptly changes at the onset of the phase transition. In this experiment, the NMR frequency is set at $55 \mathrm{MHz}$.

assume that two independent thermally activated relaxation processes are associated with the rotational motion in the two different structures that interconvert at the phase transition. We then proceeded to fit the data to the Kubo-Tomita formula, ${ }^{3-5,18} \tau_{\mathrm{c}}=\tau_{0} \exp \left(E_{\mathrm{a}} / \mathrm{k} T\right)$. Here we do not have data at different magnetic fields that would permit a reliable determination of both $\tau_{0}$ and $E_{\mathrm{a}}$. However, let us point out that the attempt frequency $\tau_{0}$ is a characteristic frequency of a specific, freely moving rotor, here 1,4-bis(ethynyl)bicyclo- 
[2.2.2] octane (BCO), and in principle does not depend on its environment. Therefore, it is legitimate to assume $\tau_{0} \approx 2 \times$ $10^{-13} \mathrm{~s}$, close to values typically found for BCO rotators (Table 1 ). With this value the fit (Figure 5) afforded rotational barriers of $620 \mathrm{~K}=1.23 \mathrm{kcal} \mathrm{mol}^{-1}$ and $820 \mathrm{~K}=1.63 \mathrm{kcal} \mathrm{mol}^{-1}$ for the high and low temperature phases, respectively. Note that the barrier for rotational motion in the high temperature phase is among the lowest ones recently reported for the ultrafast $\mathrm{BCO}$ rotators in $\mathrm{BIBCO}^{3}\left(1.48 \mathrm{kcal} \mathrm{mol}^{-1}\right.$ and $\left.745 \mathrm{~K}\right)$ or a $\mathrm{BCO}$ steroidal rotator ${ }^{2 \mathrm{a}}\left(1.15 \mathrm{kcal} \mathrm{mol}^{-1}\right.$ and $\left.579 \mathrm{~K}\right)$. Note that the set value of attempt frequency appears in hindsight reasonable since by comparing (Figure 5) the experimental data points and the simulation the apparent width of the transition is similar to that determined by X-ray.

The solid blue line in Figure 5 represents the rotational frequency, defined as $1 / 2 \pi \tau_{\mathrm{c}}$ where $\tau_{\mathrm{c}}$ is the correlation time, above and below the phase transition. Calculated with the Kubo-Tomita formula using the activation energies determined above, the maximum of the relaxation rate occurs when the rotation frequency matches the NMR (Larmor) frequency. We now discuss the origin at the microscopic level of the abrupt switching of the crystalline rotors at the onset of the phase transition from a very low-energy 4-fold equilibrium state, in which the rotation is ultrafast $(9.6 \mathrm{GHz}$ at $145 \mathrm{~K})$, to a single high-energy state associated with a slower motion $(2.3 \mathrm{GHz}$ at $145 \mathrm{~K})$, as exemplified in Figure 5.

Modulation of Transverse $\mathrm{C}-\mathrm{H}_{\text {rotator }}{ }^{\cdots \mathrm{I}_{\text {stator }}}$ Interactions Across Transition Is Key to Rotators' Dynamics. When $\mathbf{2}$ is considered alone, the calculated energy barrier for rotation, after optimization of the positions of the eight $\mathrm{C}$ atoms and $12 \mathrm{H}$ atoms of the rotator, is only $0.1 \mathrm{kcal} \mathrm{mol}^{-1}$. When moving to the crystalline state, the first step in the analysis of the rotational barrier consists of sorting out the interactions in which the eight rotator's hydrogen atoms are (or may be) implicated during the rotational process. In the present case, the $\mathrm{BCO}$ rotators interact with their surroundings by the set of $\mathrm{C}-\mathrm{H}_{\text {rotator }} \cdots \mathrm{I}_{\text {stator }}$ hydrogen bond interactions (Table S2, Supporting Information) that change significantly at the transition (Figure 6). Note that fluorine being such a poor acceptor, ${ }^{19}$ four long $\mathrm{C}-\mathrm{H}_{\text {rotator }} \cdots \mathrm{F}_{\text {stator }}$ contacts are also listed in Table S2 and drawn in Figure 6, yet their contribution to the
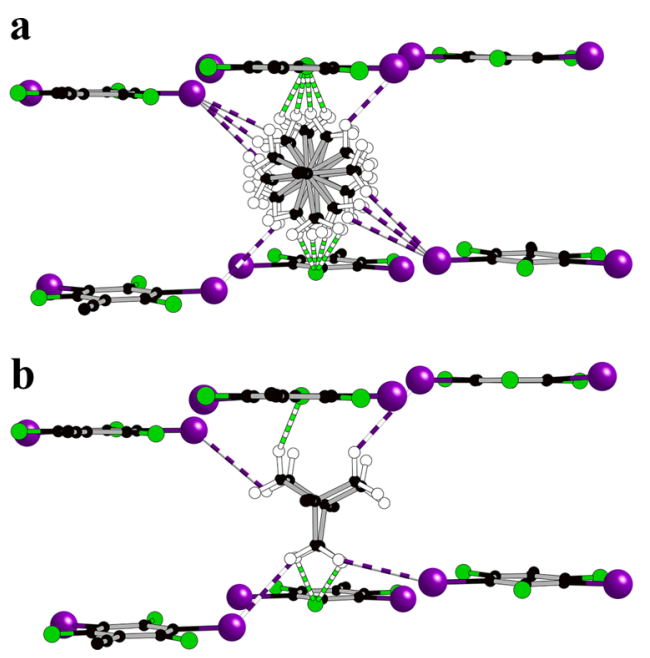

Figure 6. Change in $\mathrm{C}-\mathrm{H}_{\text {rotator }} \cdots \mathrm{I}_{\text {stator }}$ hydrogen bond (white and purple cylinders) manifold between the (a) $293 \mathrm{~K}$ and (b) $90 \mathrm{~K}$ structures $\left(\mathrm{C}-\mathrm{H}_{\text {rotator }} \cdots \mathrm{F}_{\text {stator }}\right.$ contacts: white and green cylinders $)$ of 2 . interaction of the rotators with their environment is expected to be marginal.

BCO Rotators Rub onto Their Environment by C$\mathrm{H}_{\text {rotator }} \boldsymbol{\cdots}_{\text {stator }}$ Interactions. To simulate the rotational motion in the crystal, we have taken into account one central molecule 2 and the six neighbors of Figure 6 . Since the hydrogen atoms of the central rotator do not make short contacts with the rotating moieties of the neighbors, we have modeled the neighboring molecules by 2,4,6-trifluoro-3,5-diiodophenyl acetylene fragments. On the basis of previous results, ${ }^{4}$ the barriers were calculated by optimizing the six $-\mathrm{CH}_{2}$ groups of the rotator for every value of the rotational angle $\theta$ and keeping the neighboring units fixed as in the crystal structure. The barrier for the rotation of $\mathbf{2}$ in the structure at $90 \mathrm{~K}$ is predicted to be $3.7 \mathrm{kcal} \mathrm{mol}^{-1}$, whereas at $298 \mathrm{~K}$ it is only $2.0 \mathrm{kcal} \mathrm{mol}^{-1}$ (see Figure 7a). To address the question of the possible role of $\mathrm{C}-\mathrm{H}_{\text {rotator }} \cdots \mathrm{F}_{\text {stator }}$ interactions, we have carried out a second series of calculations in which the four neighboring fragments associated with the $\mathrm{C}-\mathrm{H}_{\text {rotator }} \cdots \mathrm{I}_{\text {stator }}$ interactions were removed. Consequently, the new energy barriers will almost exclusively originate from $\mathrm{C}-\mathrm{H}_{\text {rotator }} \cdots \mathrm{F}_{\text {stator }}$ interactions. As shown in Figure $7 \mathrm{~b}$, the two rotational processes involve a very low barrier smaller than $1 \mathrm{kcal} \mathrm{mol}^{-1}$, and thus we conclude that the larger barrier at $90 \mathrm{~K}$ must be mostly due to the $\mathrm{C}-$ $\mathrm{H}_{\text {rotator }} \cdots \mathrm{I}_{\text {stator }}$ interactions.

Although these results are qualitatively in good agreement with the crystal structure analyses, we must wonder about the relatively large energy difference between the two rotational barriers. Note that although some assumption had to be done for the fitting, the ${ }^{1} \mathrm{H}$ spin-lattice relaxation suggests a smaller difference. We thus need to examine if the difference is quantitatively significant or if it may originate from some computational inadequacy.

BIBCO Case Study: Calculations Need to Relax Repulsive Interactions. A convenient system to scrutinize this aspect is provided by the ultrafast rotor BIBCO (Scheme 1). ${ }^{3}$ The structure of this system contains two crystallographically different layers of the BIBCO rotor and exhibits a phase transition at $110 \mathrm{~K}$. There is experimental evidence of two dynamic processes simultaneously present over the entire temperature range studied, associated with the rotational motion of the BCO units of the different layers with activation energies of 1.48 and $2.75 \mathrm{kcal} \mathrm{mol}^{-1}$. Since we have in this case precise crystal structures and energy barriers, we decided to consider the two rotational processes using exactly the same approach as before. Thus, one rotator of layer A (associated with $\mathrm{C}-\mathrm{H}_{\text {rotator }} \cdots \mathrm{I}_{\text {stator }}$ of 3.295 and $3.274 \AA$ and an activation energy of $2.75 \mathrm{kcal} \mathrm{mol}^{-1}$ ) and one rotator of layer $\mathrm{B}$ (associated with $\mathrm{C}-\mathrm{H}_{\text {rotator }} \cdots \mathrm{I}_{\text {stator }}$ contacts of 3.072 , 3.094, and $3.296 \AA$ and an activation energy of $1.48 \mathrm{kcal} \mathrm{mol}^{-1}$ ) were studied. To our surprise the calculated energy barriers were found to be $0.7 \mathrm{kcal} \mathrm{mol}^{-1}$ for the second but $7.0 \mathrm{kcal} \mathrm{mol}^{-1}$ for the first! Clearly the barrier associated with the longer C$\mathrm{H}_{\text {rotator }} \cdots \mathrm{I}_{\text {stator }}$ interaction in the stable structure is grossly overestimated. Analysis of the evolution of the geometric details along the rotation made clear that very short $\mathrm{C}-\mathrm{H}_{\text {rotator }} \cdots \mathrm{I}_{\text {stator }}$ contacts (around $2.7 \AA$ ) were generated around the transition state for the rotators of layer A but not for those of layer B. Thus, because of these very short $\mathrm{C}-\mathrm{H}_{\text {rotator }} \cdots \mathrm{I}_{\text {stator }}$ distances, the initial stabilizing interaction becomes strongly repulsive around the transition state and is largely responsible for the rotational barrier (i.e., the system moves from the weakly attractive region of the $\mathrm{I} \cdots \mathrm{H}$ interaction to the repulsive region 
a)

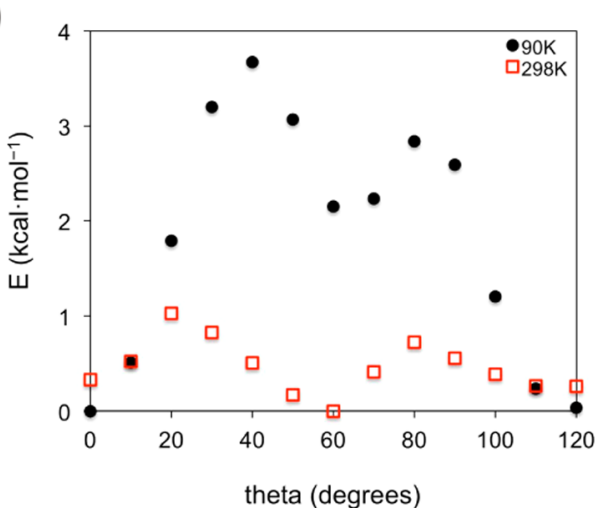

b)

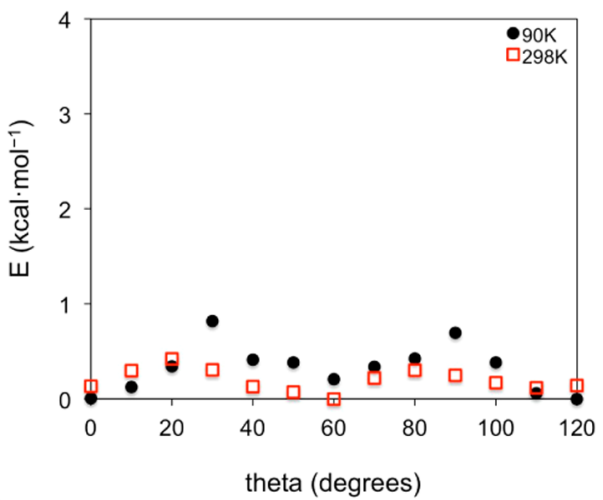

c)

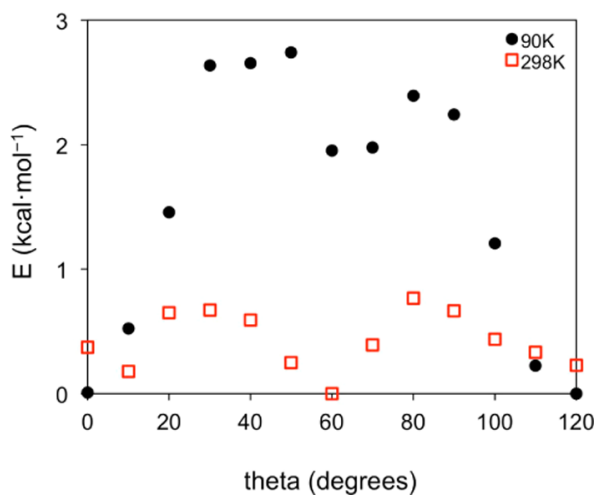

Figure 7. Calculated rotational energy barriers for 2 at $90 \mathrm{~K}$ (black circles) and $298 \mathrm{~K}$ (red squares) when the six $-\mathrm{CH}_{2}$ groups of the rotators are allowed to relax: (a) considering the six fragments of Figure 6 modeling the environment as fixed; (b) considering only two of the fragments of Figure 6, those associated with the $\mathrm{C}-\mathrm{H}_{\text {rotator }} \cdots$ $\mathrm{F}_{\text {stator }}$, which were also taken as fixed; and (c) considering the six fragments of Figure 6 and allowing also the iodine atoms of the environment to relax (see Table S3 and Figure S2, Supporting Information).

along the rotation). This makes clear the computational flaw of our previous computations: in such systems, not only the atoms of the rotating unit must be optimized but also those associated with the growing repulsive interactions with the environment. When these calculations are repeated in such a way, the barrier for the rotor of layer A becomes $2.5 \mathrm{kcal} \mathrm{mol}^{-1}$, in excellent agreement with experiment, while that for the rotators of layer $\mathrm{B}$ remains essentially unaltered. Thus, in dealing with these systems one must always check whether some interaction between the hydrogen atoms of the rotator and the environment becomes short enough in the course of the calculated rotational motion to become substantially repulsive.
In that case, the environment cannot be kept as found in the crystal structure. However, the computational settings chosen seem to be adequate: Tests using larger basis sets led to very small changes in the calculated barriers.

Calculated Rotational Barriers in 2. With these results in mind, we came back to 2 and indeed found out that some C$\mathrm{H}_{\text {rotator }} \cdots \mathrm{I}_{\text {stator }}$ around the transition state for the system at $90 \mathrm{~K}$ were too short to justify keeping the environment fixed. We thus repeated the calculations by also allowing the iodine atoms of the neighbor fragments to relax (see Figure $7 \mathrm{c}$ ). For the structure at $90 \mathrm{~K}$, there is a decrease of the rotation barrier, from 3.7 to $2.7 \mathrm{kcal} \mathrm{mol}^{-1}$. The shortest $\mathrm{I} \cdots \mathrm{H}$ contacts are relaxed and the barrier becomes somewhat smaller. For the structure at $298 \mathrm{~K}$, the estimated barrier is only reduced from 1.0 down to $0.8 \mathrm{kcal} \mathrm{mol}^{-1}$. The $\mathrm{I} \cdots \mathrm{H}$ contacts along the rotational process in this structure are not so short, so the effect of the relaxation of the iodine atoms of the neighboring rotators is almost negligible. Consequently, we conclude that the rotational barrier of $\mathbf{2}$ at room temperature is very low, on the order of $1 \mathrm{kcal} \mathrm{mol}^{-1}$, and should distinctly increase below the transition (by ca. $1.5-2 \mathrm{kcal} \mathrm{mol}^{-1}$ according to our calculation) because the asymmetric environment resulting from the optimization of halogen bonding at the transition results with too short $\mathrm{C}-\mathrm{H}_{\text {rotator }} \cdots \mathrm{I}_{\text {stator }}$ contacts during the rotation.

Handedness of BCO Rotators, Mutamer-Induced Second-Harmonic Generation, and Optical Dimensionality. Second-harmonic generation (SHG) microscopy experiments were carried out in a single crystal of 2 . SHG is wellknown for its properties as an effective device to probe the chirality of a material. Although the space group of crystal $\mathbf{2}$ is centrosymmetric and SHG should be expected to be absent, a SHG signal (Figure 8c) was recorded. The occurrence of that nontrivial SHG signal lies with the fact that the centrosymmetric structure obtained from the X-ray diffraction experiment is nothing else but a conformational "average" over a multitude of configurations, most of which are chiral. In fact, although energy considerations suggest that the centrosymmetric structure is the most prominent of all possible configurations in the crystal, each of the less-likely chiral configurations breaks the space-inversion symmetry allowing a SHG signal to be generated. This unexpected emergence of SHG has been discussed in a recent publication. ${ }^{5 a}$ Its effect has been referred to as "mutamer-induced SHG", for it is generated by a multitude of conformational mutations, which are only slightly more expensive energetically that the centrosymmetric structure. The maximum intensity in the SHG experiment that we carried out occurred for a polarization angle of the incident beam of $15^{\circ}$ off the direction of the s polarization. For that angle, the best possible alignment with respect to the unique rotators' axles director in the one-dimensional lattice was achieved. Note that even though that would not be practical in the present crystal orientation, a crystal-on-loop tilt by $45^{\circ}$ around the vertical axis in Figure $8 \mathrm{~b}$ can allow one to neatly align the horizontal polarization closer (modulo the $15^{\circ}$ offset) to the director of the rotors' axles, thereby reaching a larger SHG response.

As mentioned above, and demonstrated recently for the dirotor bis((4-(4-pyridyl)-ethynyl)bicyclo[2.2.2] oct-1-yl)buta1,3 -diyne, ${ }^{\text {sa }}$ this is evidence of random dynamic conformational switching in the handedness of the rotor helices which at room temperature can undergo mutations while preserving on the average the space-inversion symmetry of the lattice. ${ }^{\text {sa }}$ This 
a

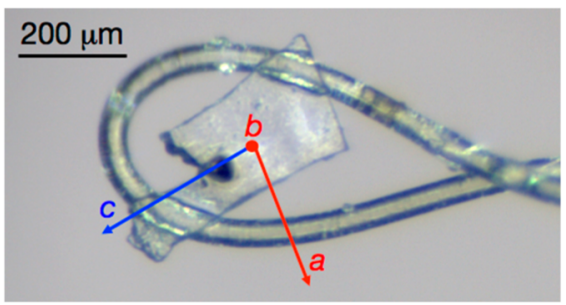

b

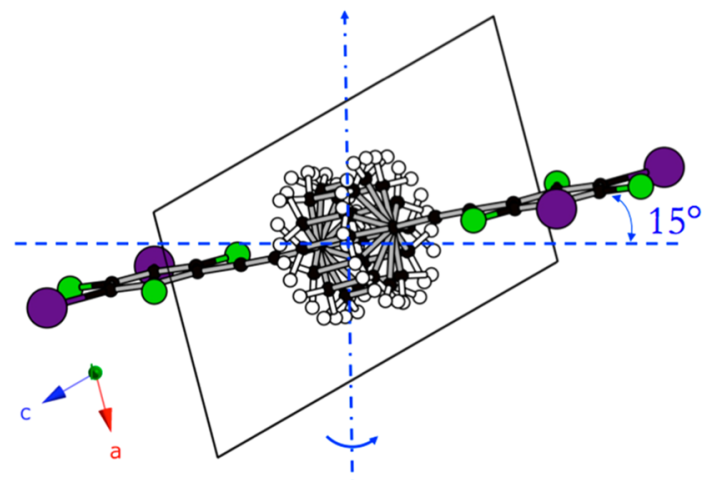

c

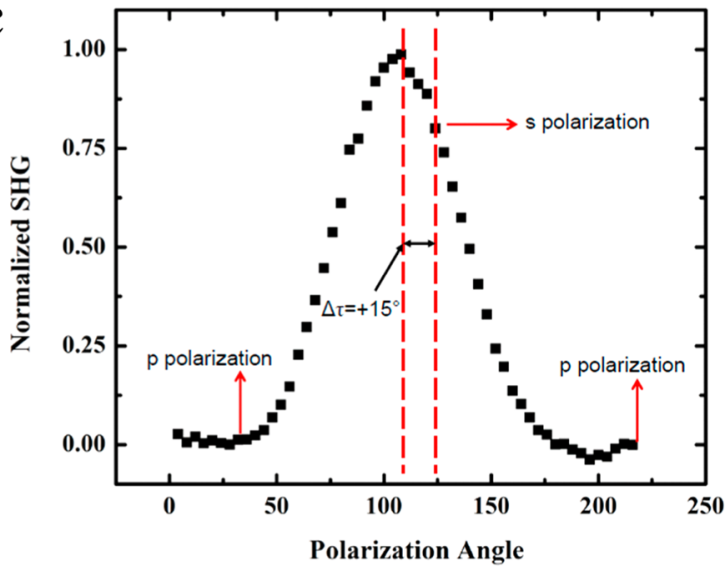

Figure 8. (a) With the crystal set on a nylon loop on this orientation, the laser light propagates along $b$; (b) orientation of any rotator axle as seen by the p polarization in this crystal position; (c) SHG intensity of the single crystal of $\mathbf{2}$ shown in (a) as a function of the incident laser polarization.

result is another convincing example of the utility of polarized light to probe the torsional degree of freedom of the chiral helix blades, and thereby the symmetry ${ }^{20}$ and dimensionality ${ }^{5 a}$ of large collections of molecular rotors in the solid state.

\section{CONCLUSIONS}

We reported results from variable-temperature X-ray and static single crystal ${ }^{1} \mathrm{H}$ spin-lattice relaxation experiments and rotational barrier calculations along with an in-depth description and interpretation of the way in which the dynamics of the $\mathrm{BCO}$ rotators in the crystalline arrays of the novel, self-assembled 1,4-bis((2,4,6-trifluoro-3,5-diiodophenyl)ethynyl)bicyclo[2.2.2] octane rigid strut 2 changes back and forth across a reversible transition at $145 \mathrm{~K}$. As borne out from our observations, the reversible change seen in the rotational barriers at the transition is due to a squeezing of the rotators' $\mathrm{C}-\mathrm{H}_{\text {rotator }} \cdots \mathrm{I}_{\text {stator }}$ hydrogen bond cloud across the $\mathrm{C}-\mathrm{I}_{\text {stator }} \cdots$ $\mathrm{I}_{\text {stator }}-\mathrm{C}$ halogen bond-mediated phase transition. Below $145 \mathrm{~K}$ the two halogen-bonded planes, between which any rotator is sandwiched, become nonequivalent, and short $\mathrm{C}-\mathrm{H}_{\text {rotator }} \cdots \mathrm{I}_{\text {stator }}$ interactions, adding an extra repulsive component to the rotational barrier, are generated during the rotational motion. Altogether, the control exerted by the change of structure alters the dynamics of the crystalline rotors, braking suddenly their rotation from 9.6 to $2.3 \mathrm{GHz}$ at $145 \mathrm{~K}$ - the onset of the transition. At the same time, the rotors switch from a very lowenergy 4-fold degenerate equilibrium state, initially occupied, to a single higher-energy equilibrium state. In the high temperature regime, $T_{1}^{-1}$ was found to take very small values owing to the fact that the rotational barrier is so low $\left[1.23 \mathrm{kcal} \mathrm{mol}^{-1}\right.$ $(620 \mathrm{~K})]$ and the frequency of the rotation so high compared to the ${ }^{1} \mathrm{H}$ Larmor frequency $(55 \mathrm{MHz})$ at $1 \mathrm{~T}$ that the relaxation is inefficient. At the onset of the phase transition, $T_{1}^{-1}$ values increase on account both of the higher rotational barrier $\left[1.63 \mathrm{kcal} \mathrm{mol}^{-1}(820 \mathrm{~K})\right]$ and of the lower temperatures. The rotational frequency keeps on decreasing and $T_{1}^{-1}$ keeps on increasing up to $100 \mathrm{~K}$ where the rotational frequency is seen to match with the ${ }^{1} \mathrm{H}$ Larmor frequency ( 55 $\mathrm{MHz}$ ) for a magnetic field of $1 \mathrm{~T}$.

\section{EXPERIMENTAL SECTION}

Materials and Methods. Recycling HPLC-preparative-SEC, Japan Analytical Industry co. Ltd. THF, with UV detector (wavelength 290 $\mathrm{nm}$, pressure $054 \mathrm{Kgf} / \mathrm{cm}^{2}$, flow $\left.3.5 \mathrm{~mL} / \mathrm{min}\right)$.

Synthesis of 1-Ethynyl-4-((2,4,6-trifluoro-3,5-diiodophenyl)ethynyl)bicyclo[2.2.2]octane, 1. A solution of 1,4-bis(ethynyl)bicyclo[2.2.2] octane $(116 \mathrm{mg}, 0.74 \mathrm{mmol})$ dissolved in triethylamine $(70 \mathrm{~mL})$ was sparged with argon for $15 \mathrm{~min}$ and added to a solid mixture of 1,3,5-trifluoro-2,4,6-triiodobenzene ${ }^{21}(107 \mathrm{mg}, 0.21 \mathrm{mmol})$ and catalytic amounts (ca. $16 \mathrm{~mol} \%)$ of $\left[\mathrm{Pd}\left(\mathrm{PPh}_{3}\right)_{4}\right]$ and $\mathrm{CuI}(15 \mathrm{~mol}$ $\%)$. The reaction mixture was heated at $60{ }^{\circ} \mathrm{C}$ overnight under argon. Reaction progress was monitored by thin layer chromatography (methylene chloride/ $n$-hexane: 50/50) and by mass spectroscopy $\left(\mathrm{FAB} / \mathrm{EI}^{+}\right)$. The reaction mixture was poured in a methylene chloride and saturated ammonium chloride solution (50:20). The organic layer was dried over magnesium sulfate, filtered, and evaporated to dryness under low pressure to afford a yellowish solid residue $(150 \mathrm{mg})$. A mass spectroscopy analysis $\left(\mathrm{FAB} / \mathrm{EI}^{+}\right)$reveals a mixture of compounds that includes $\mathbf{1}(\mathrm{m} / z=540.2), \mathbf{2}(\mathrm{m} / z=922.1)$, and $\mathbf{3}(\mathrm{m} / z=1334.2)$. Purification involves a two-step flash-filtration using a gradient such as $100 \%$ methylene chloride then ethanol/methylene chloride (10:90) to yield a whitish solid $(130 \mathrm{mg})$ that is purified by HPLC-preparative SEC using THF as eluent. After three recycles, the majority compound $1(50 \mathrm{mg}, 93 \mu \mathrm{mol})$ was successfully isolated with $44 \%$ yield as a white solid characterized by mass spectroscopy $\left(\mathrm{FAB} / \mathrm{EI}^{+}\right)(\mathrm{m} / z=540.2$ $\left.\left[\mathrm{M}^{+}\right]\right)$and finally directly engaged in the second step of the synthesis.

Synthesis of 1,4-Bis((2,4,6-trifluoro-3,5-diiodophenyl)ethynyl)bicyclo[2.2.2]octane, 2. Following the same procedure that for the first step, a solution of 1-ethynyl-4-((2,4,6-trifluoro-3,5diiodophenyl)ethynyl)bicyclo[2.2.2] octane 1 was added to a solid mixture of 1,3,5-trifluoro-2,4,6-triiodobenzene ${ }^{22}(120 \mathrm{mg}, 0.24 \mathrm{mmol})$ and catalytic amounts (ca. $16 \mathrm{~mol} \%)$ of $\left[\mathrm{Pd}\left(\mathrm{PPh}_{3}\right)_{4}\right]$ and $\mathrm{CuI}(15 \mathrm{~mol}$ $\%),(50 \mathrm{mg}, 93 \mu \mathrm{mol})$ dissolved in triethylamine $(70 \mathrm{~mL})$. The reaction mixture was heated at $80^{\circ} \mathrm{C}$ for $24 \mathrm{~h}$. Reaction progress was monitored by thin layer chromatography (methylene chloride/ $n$ hexane: $20 / 80)$ and mass spectroscopy $\left(\mathrm{FAB} / \mathrm{EI}^{+}\right)(\mathrm{m} / z=922.1$, $\left.\left[\mathrm{M}^{+}\right]\right)$. Addition of $\mathrm{PdCl}_{2}\left(\mathrm{PPh}_{3}\right)_{2}(10 \mathrm{~mol} \%)$ and $\mathrm{CuI}(10 \mathrm{~mol} \%)$ after $10 \mathrm{~h}$ was required to increase the reaction advancement. After the usual work-up, a yellowish solid residue was obtained which was purified in a two step flash chromatography (Versa Flash Supelo) using a $100 \% n$-hexane gradient, then methylene chloride/ $n$-hexane (10:90) to afford a whitish powder which was finally purified by HPLCpreparative-SEC using THF as the eluent to yield compound 2 (15 $\mathrm{mg}, 16 \mu \mathrm{mol}$ ) with $17 \%$ yield. Colorless plate-like crystals were obtained after slow evaporation in THF $\left(\mathrm{mp}>320^{\circ} \mathrm{C}\right) ;{ }^{1} \mathrm{H}$ NMR $\left(\right.$ THF- $\left.d_{8}, 300 \mathrm{MHz}\right) \delta 2.0(\mathrm{~s}, 12 \mathrm{H}) ;{ }^{13} \mathrm{C}$ NMR $\left(\right.$ THF- $\left.d_{8}, 300 \mathrm{MHz}\right) \delta$ 
$165.70(\mathrm{~m}), 162.37(\mathrm{~m}), 160.41$ (m), 108.48, 108.46, 99.81, 99.75, 31.97, 28.23; $\mathrm{SM}\left(\mathrm{FAB} / \mathrm{EI}^{+}\right) m / z=922.1\left[\mathrm{M}^{+}\right]$.

Crystal Structures. X-ray single crystal diffraction data were collected at 293 and $90 \mathrm{~K}$ using a Bruker Nonius Kappa CCD diffractometer with Mo $\mathrm{K} \alpha$-radiation $(\mu=0.71073 \AA)$ equipped with an Oxford Cryosystems cryostream cooler. Combined $\varphi$ - and $\omega$-scans were used for data collection. An empirical absorption correction of experimental intensities was applied for all data using the SADABS program. ${ }^{22}$ A reversible structural phase transition was detected by measuring lattice parameters in the temperature range $90-300 \mathrm{~K}$ with $2-20^{\circ}$ steps during cooling and heating of the crystal at $2{ }^{\circ} \mathrm{C} / \mathrm{min}$ rate (Figure S2, Supporting Information). Below $145 \mathrm{~K}$, additional reflections appeared, indicating a doubling of the unit cell; the transformation matrix from 293 to $90 \mathrm{~K}$ lattices reads: ( $010,10-1$, -200 ). The structures were solved by a direct method followed by Fourier syntheses and refined by a full-matrix least-squares method using the SHELX-97 programs. $^{23}$ All non-hydrogen atoms were refined in an anisotropic approximation. $\mathrm{H}$ atoms were placed in idealized positions and refined using a riding model with isotropic thermal parameters $U_{\text {iso }}(\mathrm{H})=1.2 U_{\mathrm{eq}}(\mathrm{C})$. Details of the experimental data collection and structure refinements are summarized in Table S1, Supporting Information. Crystal data for $2, \mathrm{C}_{24} \mathrm{H}_{12} \mathrm{~F}_{6} \mathrm{I}_{4}, M_{\mathrm{r}}=921.94$, triclinic $P \overline{1}$, at $293 \mathrm{~K}: a=7.0104(3), b=9.1585(6), c=10.9366(6) \AA$, $\alpha=80.332(6)^{\circ}, \beta=73.993(4)^{\circ}, \gamma=84.208(4)^{\circ}, V=664.26(6) \AA^{3}, Z$ $=1, \mu=47.44 \mathrm{~cm}^{-1}, 2 \Theta \max =60^{\circ}, 26080$ reflections measured, 3855 unique $\left(R_{\text {int }}=0.0344\right), 199$ parameters refined, $R\left(F_{2}\right)=0.0429$, $w R\left(F^{2}\right)=0.1120, \mathrm{GOF}=1.085$. At $90 \mathrm{~K}$ : triclinic $P \overline{1}, a=9.0986(5), b$ $=11.2261(7), c=13.7829(6) \AA, \alpha=112.913(5)^{\circ}, \beta=96.345(5)^{\circ}, \gamma=$ 93.942(5) ${ }^{\circ}, V=1279.1(1) \AA^{3}, Z=2, \mu=49.27 \mathrm{~cm}^{-1}, 2 \Theta \max =79.6^{\circ}$, 75631 reflections measured, 3855 unique $\left(R_{\text {int }}=0.0296\right), 307$ parameters refined, $R\left(F^{2}\right)=0.0262, w R\left(F^{2}\right)=0.0491, \mathrm{GOF}=1.075$.

$V T{ }^{1} \mathrm{H}$ Spin-Lattice Relaxation Time $\left(T_{1}\right)$. Experiments were carried out as described previously ${ }^{4,5}$ on one static single crystal at a ${ }^{1} \mathrm{H}$ Larmor frequencies of $55 \mathrm{MHz}$ ) and over a wide range of temperatures using a NMR spectrometer and probe built at Orsay. The probe is designed so as to reduce spurious proton signals. The crystal was loaded into a small glass tube (typically $1.2 \mathrm{~mm}$ in diameter) on which the NMR coil was wound. ${ }^{1} \mathrm{H}$ signals were recorded using the FID following a $\pi / 2$ pulse (typically $0.8-1.5 \mu \mathrm{s}$ ) and spin-lattice relaxation was measured using the standard saturation recovery sequence. For each $T_{1}$ measurement, we recorded signals for 20 values of the relaxation delay between the saturating comb and the measuring pulse.

Computational Details. Calculations were performed as described previously $y^{5}$ using the hybrid M06-2X functional ${ }^{24}$ and the 6-31G(d,p) basis set ${ }^{25}$ as implemented in the Gaussian09 package. $^{26}$

Second-Harmonic Generation Microscopy Experiments. The SHG efficiency of one single crystal was investigated by means of a SHG microscopy setup described earlier. ${ }^{5 a}$

\section{ASSOCIATED CONTENT}

\section{S Supporting Information}

Figures S1 and S2, Tables S1-3 and cif files. This material is available free of charge via the Internet at http://pubs.acs.org.

\section{AUTHOR INFORMATION}

\section{Corresponding Author}

*E-mail: patrick.batail@univ-angers.fr.

\section{Present Addresses}

O(C.L.) Institut Néel, 25 avenue des Martyrs, Bâtiment F, BP 166, 38042 Grenoble cedex 9, France.

-(H.M.Y.) Institute for Molecular Science, Myodaiji, Okazaki, Aichi 444-8585, Japan.

\section{Notes}

The authors declare no competing financial interest.

\section{ACKNOWLEDGMENTS}

P.B. and C.L. thank the Advanced Science Institute, RIKEN for Senior Visiting Scientist and internship grants, respectively. C.L. thanks the CNRS and the Région des Pays de la Loire for a Ph.D. grant. K.I. thanks the Région des Pays de la Loire for a postdoctoral grant. This research was funded at Angers and Orsay by the CNRS and by the Région des Pays de la Loire Grant MOVAMOL and the joint CNRS-Russian Federation Grants PICS 6028 and RFBR-CNRS 12-03-91059 (Chernogolovka). Work at RIKEN was supported by Grant-in-Aid for Scientific Research (S) (No. 22224006) from the Japan Society for the Promotion of Science (JSPS). Work in Bellaterra and Tarragona was supported by the Spanish Ministerio de Economía y Competitividad (Projects FIS2012-37549-C05-05, CTQ2011-29054-C02-01 and CSD 2007-00041). We thank Guillaume Bastien for his help in the sample preparation for tNMR experiments.

\section{ABBREVIATIONS}

BCO, 1,4-bis(ethynyl)bicyclo[2.2.2] octane; BIBCO, 1,4-bis(iodoethynyl)bicycle[2.2.2] octane; BABCO, 1,4-bis(carboxyethynyl)bicyclo[2.2.2] octane; p-BIB, 1,4-bis(iodoethynyl)benzene

\section{REFERENCES}

(1) (a) Sauvage, J.-P. Acc. Chem. Res. 1998, 31, 611. (b) Koumura, N.; Zijlstra, R. W. J.; R. A. van Delden, R. A.; Harada, N.; Feringa, B. L. Nature 1999, 401, 152. (c) Pease, A. R.; Jeppesen, J. O.; Stoddart, J. F.; Luo, Y.; Collier, C. O.; Heath, J. R. Acc. Chem. Res. 2001, 34, 433. (d) Feringa, B. L. Acc. Chem. Res. 2001, 34, 504. (e) Leigh, D. A.; Wong, J. K. Y.; Dehez, F.; Zerbetto, F. Nature 2003, 424, 174. (f) Jian, H.; Tour, J. M. J. Org. Chem. 2003, 68, 5091. (g) van Delden, R. A.; Wiel, M. K. J.; Pollard, M. M.; Vicario, J.; Koumura, N.; Feringa, B. L. Nature 2005, 437, 1337. (h) Horinek, D.; Michl, J. Proc. Natl. Acad. Sci. U.S.A. 2005, 102, 14175. (i) Kottas, G. S.; Clarke, L. I.; Horinek, D.; Michl, J. Chem. Rev. 2005, 105, 1281. (j) Kinbara, K.; Aida, T. Chem. Rev. 2005, 105, 1377. (k) Browne, W. R.; Feringa, B. L. Nat. Nanotechnol. 2006, 1, 25-35. (1) Shirai, Y.; Morin, J.-F.; Sasaki, T.; Guerrero, J. M.; Tour, J. M. Chem. Soc. Rev. 2006, 35, 1043. (m) Kay, E. R.; Leigh, D. A.; Zerbetto, F. Angew. Chem., Int. Ed. 2007, 46, 72. (n) Skopek, K.; Hershberger, M. C.; Gladysz, J. A. Coord. Chem. Rev. 2007, 251, 1723. (o) Skopek, K.; Gladysz, J. A. J. Organomet. Chem. 2008, 693, 857. (p) Conyard, J.; Addison, K.; Heisler, I. A.; Cnossen, A.; Browne, W. R.; Feringa, B. L.; Meech, S. R. Nat. Chem. 2012, 4, 547. (q) Perera, U. G. E.; Ample, F.; Kersell, H.; Zhang, Y.; Vives, G.; Echeverria, J.; Grisolia, M.; Rapenne, G.; Joachim, C.; Hla, S.-W. Nat. Nanotechnol. 2013, 8, 46. (r) Panman, M. R.; Bakker, B. H.; den Uyl, D.; Kay, E. R.; Leigh, D. A.; Jan Bumal, W.; Brouwer, A. M.; Geenevasen, J. A. J.; Woutersen, S. Nat. Chem. 2013, 5, 929. (s) Kobr, L.; Zhao, K.; Shen, Y.; Shoemaker, R. K.; Rogers, C. T.; Michl, J. Cryst. Growth Des. 2014, 14, 559.

(2) (a) Rodríguez-Molina, B.; Peŕez-Estrada, S.; Garcia-Garibay, M. A. J. Am. Chem. Soc. 2013, 135, 10388. (b) Rodríguez-Molina, B.; Farfán, N.; Romero, M.; Méndez-Stivalet, J. M.; Santillan, R.; GarciaGaribay, M. A. J. Am. Chem. Soc. 2011, 133, 7280. (c) Khuong, T.-A.; Nunez, J. E.; Godinez, C. E.; Garcia-Garibay, M. A. Acc. Chem. Res. 2006, 39, 413. (d) Karlen, S. D.; Reyes, H.; Taylor, R. E.; Khan, S. I.; Hawthorne, M. F.; Garcia-Garibay, M. A. Proc. Natl. Acad. Sc. USA 2010, 107, 14973. (e) Vogelsberg, C.; Garcia-Garibay, M. A. Chem. Soc. Rev. 2012, 41, 1892.

(3) Lemouchi, C.; Vogelsberg, C.; Simonov, S.; Zorina, L.; Batail, P.; Brown, S.; Garcia-Garibay, M. A. J. Am. Chem. Soc. 2011, 133, 6371; Correction: J. Am. Chem. Soc. 2011, 133, 13765.

(4) Lemouchi, C.; Mézière, C.; Zorina, L.; Simonov, S.; RodríguezFortea, A.; Canadell, E.; Wzietek, P.; Auban-Senzier, P.; Pasquier, C.; 
Giamarchi, T.; Garcia-Garibay, M. A.; Batail, P. J. Am. Chem. Soc. 2012, 134, 7880 .

(5) (a) Lemouchi, C.; Iliopoulos, K.; Zorina, L.; Simonov, S.; Wzietek, P.; Cauchy, T.; Rodríguez-Fortea, A.; Canadell, E.; Kaleta, J.; Michl, J.; Gindre, D.; Chrysos, M.; Batail, P. J. Am. Chem. Soc. 2013, 135, 9366. (b) Bastien, G.; Lemouchi, C.; Allain, M.; Wzietek, P.; Rodríguez-Fortea, A.; Canadell, E.; Iliopoulos, K.; Gindre, D.; Chrysos, M.; Batail, P. CrystEngComm 2014, 16, 1241.

(6) Horie, M.; Suzaki, Y.; Hashizume, D.; Abe, T.; Wu, T.; Sassa, T.; Hosokai, T.; Osakada, K. J. Am. Chem. Soc. 2012, 134, 17392.

(7) (a) Setaka, W.; Yamaguchi, K. J. Am. Chem. Soc. 2012, 134, 17932. (b) Setaka, W.; Yamaguchi, K. Proc. Natl. Acad. Sci. U.S.A. 2012, 109, 9271. (c) Setaka, W.; Yamaguchi, K. J. Am. Chem. Soc. 2012, 134, 12458. (d) Setaka, W.; Yamaguchi, K. J. Chem. Phys. C 2012, 116, 24845. (e) Setaka, W.; Yamaguchi, K. J. Am. Chem. Soc. 2013, 135, 14560.

(8) Zhang, Q.-C.; Wu, F.-T.; Hao, H.-M.; Xu, H.; Zhao, H.-X.; Long, L.-S.; Huang, R.-B.; Zheng, L.-S. Angew. Chem., Int. Ed. 2013, 52, 12602.

(9) Hoshino, N.; Takeda, T.; Akutagawa, T. RSC Adv. 2014, 4, 743.

(10) Xue, M.; Wang, K. L. Sensors 2012, 12, 11612.

(11) Trauner, D. Bellstein J. Org. Chem. 2012, 8, 870.

(12) In this paper we have adopted the nomenclature proposed by Michl $^{1,2 a}$ where the word "rotor" is reserved to describe entire molecular assemblies, and the terms "rotator" and "stator" are reserved to define the rotary units and the static frames that are used to define the frame of reference.

(13) For a perspective and selected references on halogen bonding, see: (a) Legon, A. C. Phys. Chem. Chem. Phys. 2010, 12, 7736.

(b) Fourmigué, M. Curr. Opin. Sol. State Mater. Sci. 2009, 13, 36.

(c) Bertani, R.; Sgarbossa, P.; Venzo, A.; Lelj, F.; Amati, M.; Resnati, G.; Pilati, T.; Metrangolo, P.; Terraneo, G. Coord. Chem. Rev. 2012, 254, 677. (d) Troff, R. W.; Mäkelä, T.; Topic, F.; Valkonen, A.; Raatikainen, K.; Rissanen, K. Eur. J. Org. Chem. 2013, 1617.

(14) (a) Yamamoto, H. M.; Yamaura, J.-I.; Kato, R. J. Am. Chem. Soc. 1998, 120, 5905. (b) Yamamoto, H. M.; Yamaura, J.-I.; Kato, R. Synth. Met. 1999, 102, 1448. (c) Yamamoto, H. M.; Kato, R. Chem. Lett. 2000, 970. (d) Kosaka, Y.; Yamamoto, H. M.; Nakao, A.; Kato, R. Bull. Chem. Soc. Jpn. 2006, 79, 1148. (e) Yamamoto, H. M.; Kosaka, Y.; Maeda, R.; Yamaura, J.-I.; Nakao, A.; Nakamura, T.; Kato, R. ACS Nano 2008, 2, 143. (f) Lieffrig, J.; Yamamoto, H. M.; Kusamoto, T.; Cui, H.; Jeannin, O.; Fourmigué, M.; Kato, R. Cryst. Growth Des. 2011, 11, 4267. (g) Lieffrig, J.; Jeannin, O.; Fourmigué, M. J. Am. Chem. Soc. 2013, 135, 6200.

(15) Barrès, A.-L.; El-Ghayoury, A.; Zorina, L. V.; Canadell, E.; Auban-Senzier, P.; Batail, P. Chem. Commun. 2008, 2194.

(16) Fourmigué, M.; Batail, P. Chem. Rev. 2004, 104, 5379-5418.

(17) González, L.; Gimeno, N.; Tejedor, R. M.; Polo, V.; Blanca Ros, M.; Uriel, S.; Serrano, J. L. Chem. Mater. 2013, 25, 4503.

(18) Akutagawa, T.; Koshinaka, H.; Sato, D.; Takeda, S.; Noro, S. I.; Takahashi, H.; Kumai, R.; Tokura, Y.; Nakamura, T. Nat. Mater. 2009, 8,342 .

(19) (a) Howard, J. A. K.; Hoy, V. J.; O’Hagan, D.; Smith, G. T. Tetrahedron 1996, 52, 12613. (b) Dunitz, J. D.; Taylor, R. Chem.-Eur. J. 1997, 3, 89.

(20) (a) van der Veen, M. A.; Vermoorele, F.; De Vos, D. E.; Verbiest, T. Anal. Chem. 2012, 84, 6378. (b) van der Veen, M. A.; Vermoortele, F.; De Vos, D. E.; Verbiest, T. Anal. Chem. 2012, 84, 6386.

(21) Hennrich, G.; Echavarren, A. M. Tetrahedron Lett. 2004, 45, 1147.

(22) Sheldrick, G. M. SADABS; University of Göttingen: Germany, 1996.

(23) Sheldrick, G. M. Acta Crystallogr., Sect. A 2008, 64, 112.

(24) Zhao, Y.; Truhlar, D. G. Theor. Chem. Acc. 2008, 120, 215.

(25) Hariharan, P. C.; Pople, J. A. Theoret. Chimica Acta 1973, 28, 213.

(26) Frisch, M. J.; Trucks, G. W.; Schlegel, H. B.; Scuseria, G. E.; Robb, M. A.; Cheeseman, J. R.; Scalmani, G.; Barone, V.; Mennucci,
B.; Petersson, G. A.; Nakatsuji, H.; Caricato, M.; Li, X.; Hratchian, H. P.; Izmaylov, A. F.; Bloino, J.; Zheng, G.; Sonnenberg, J. L.; Hada, M.; Ehara, M.; Toyota, K.; Fukuda, R.; Hasegawa, J.; Ishida, M.; Nakajima, T.; Honda, Y.; Kitao, O.; Nakai, H.; Vreven, T.; Montgomery Jr.; J. A., Peralta, J. E.; Ogliaro, F.; Bearpark, M.; Heyd, J. J.; Brothers, E.; Kudin, K. N.; Staroverov, V. N.; Kobayashi, R.; Normand, J.; Raghavachari, K.; Rendell, A.; Burant, J. C.; Iyengar, S. S.; Tomasi, J.; Cossi, M.; Rega, N.; Millam, J. M.; Klene, M.; Knox, J. E.; Cross, J. B.; Bakken, V.; Adamo, C.; Jaramillo, J.; Gomperts, R.; Stratmann, R. E.; Yazyev, O.; Austin, A. J.; Cammi, R.; Pomelli, C.; Ochterski, J. W.; Martin, R. L.; Morokuma, K.; Zakrzewski, V. G.; Voth, G. A.; Salvador, P.; Dannenberg, J. J.; Dapprich, S.; Daniels, A. D.; Farkas, Ö.; Foresman, J. B.; Ortiz, J. V.; Cioslowski, J.; Fox, D. J. Gaussian 09, Revision B1; Gaussian, Inc.: Wallingford CT, 2009. 